$7 \quad$ Note A

8

\title{
Increased absorption by giant aerosol particles over the
}

\section{Gangetic-Himalayan region}

\author{
Vani Starry Manoharan ${ }^{1 *}$, Rao Kotamarthi $^{1}$, Yan Feng ${ }^{1}$, Maria Caddedu ${ }^{1}$
}

${ }^{1}$ Environmental Science Division, Argonne National Laboratory, Argonne, Illinois, USA

For clarity, the absorption coefficient and spectral index values are plotted in Fig. S1 for days 135-170. In

this period, on the whole, the absorption rose to a higher value than previously. Moreover, the observed

large deviation in absorption suggests the presence of large-micron aerosol, leading to increased

absorption for $D_{1 \mu \mathrm{m}}$ particles and near-constant absorption for $\mathrm{D}_{10 \mu \mathrm{m}}$ particles. These results suggest that

12 significant amounts of super-micron particles were loaded continuously into the ambient aerosol over a

3 period of about 15-20 days, starting at about day 140, and that this caused a steady increase in absorption

4 for both $D_{1 \mu \mathrm{m}}$ and $\mathrm{D}_{10 \mu \mathrm{m}}$ particles. The level of absorption attains a peak at about day 158 . 


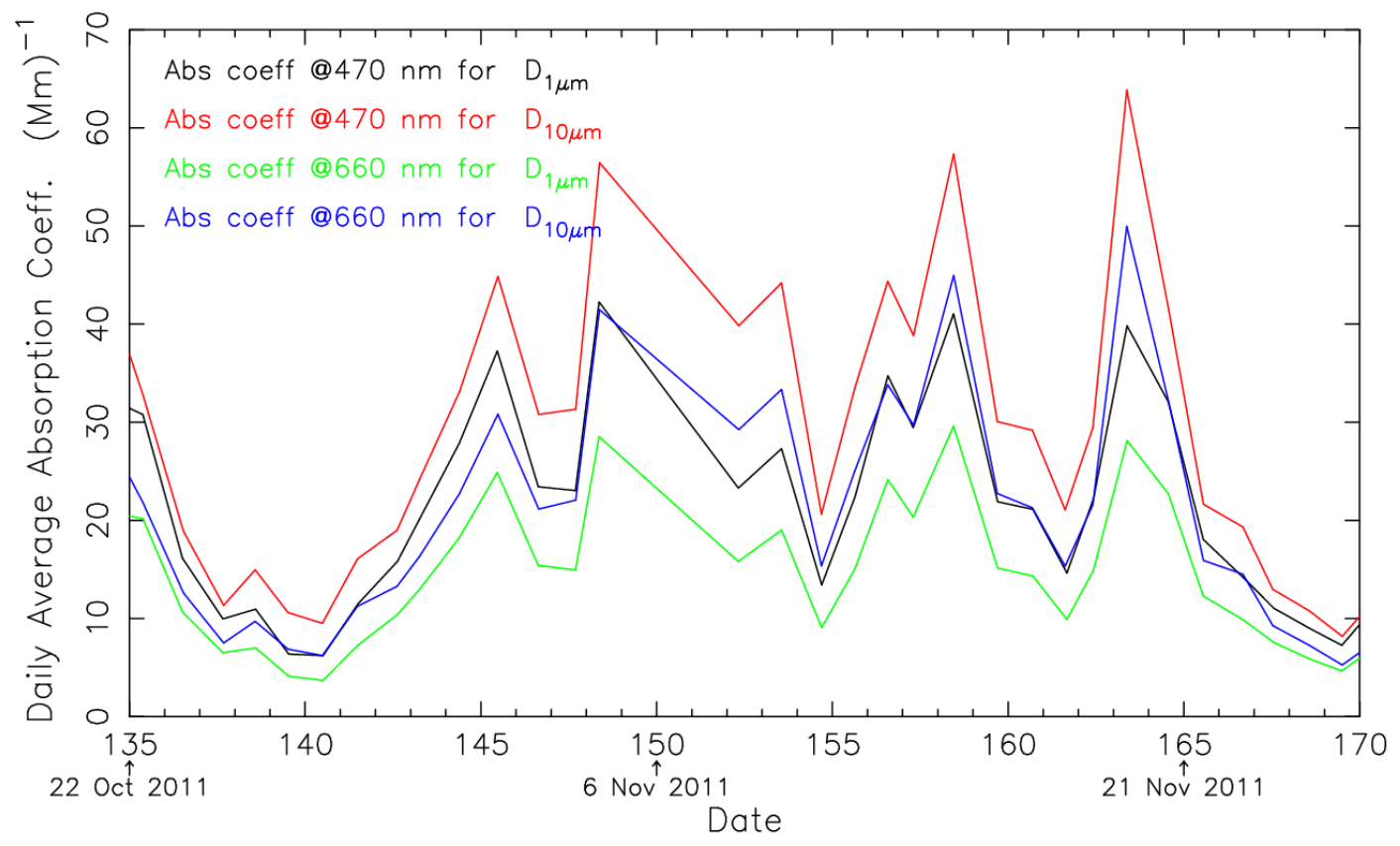

15

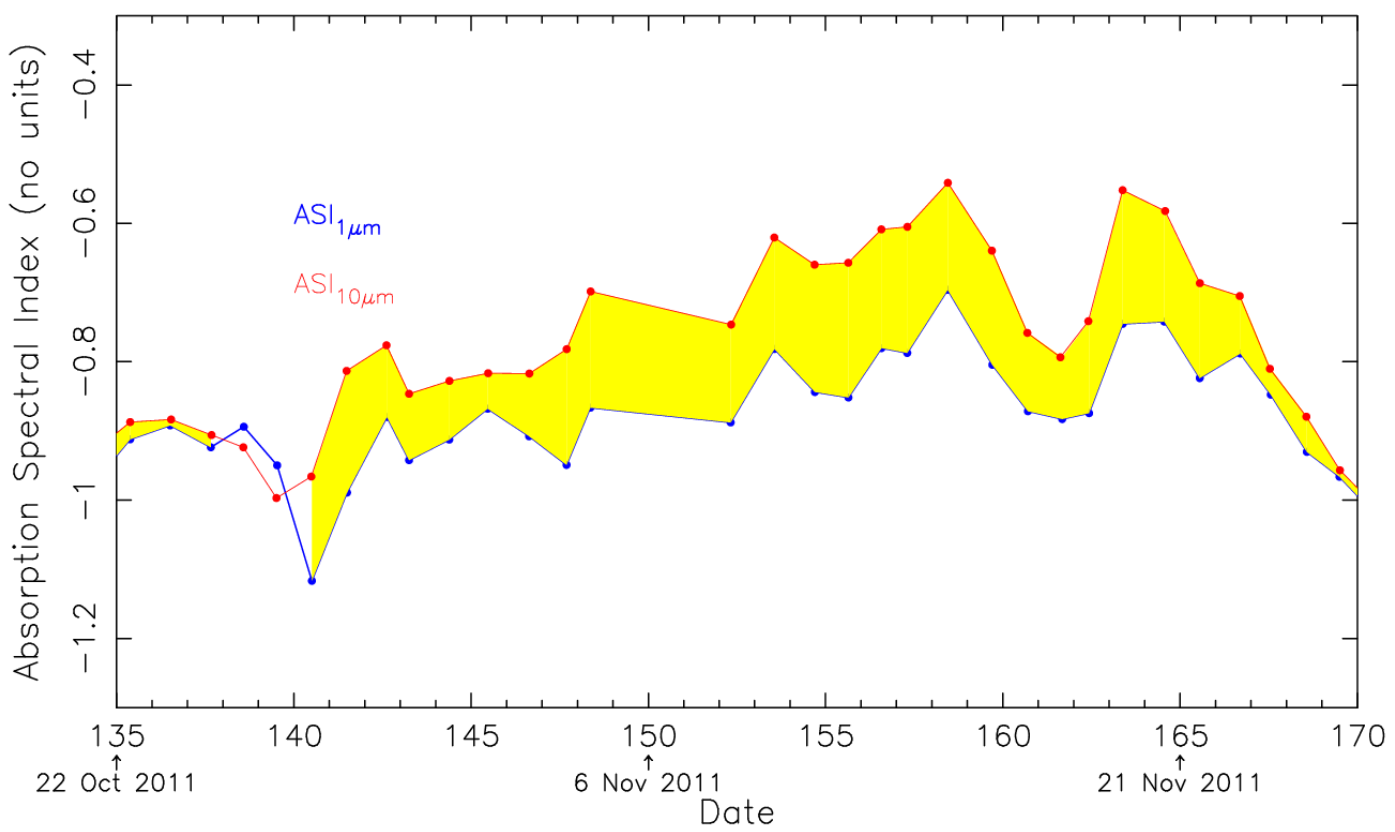

16

17 Supplementary Figure S1 - Daily averaged absorption coefficient (a) and ASI (b) for days 135-170.

18 


\section{Note B}

20 Daily variations of aerosol scattering coefficients in three wavelength bands - 450, 558 and $700 \mathrm{~nm}-$ 21 for $D_{1 \mu \mathrm{m}}$ and $\mathrm{D}_{10 \mu \mathrm{m}}$ particles from June 9, 2011, to March 31, 2012. Data are missing in the white areas.

22

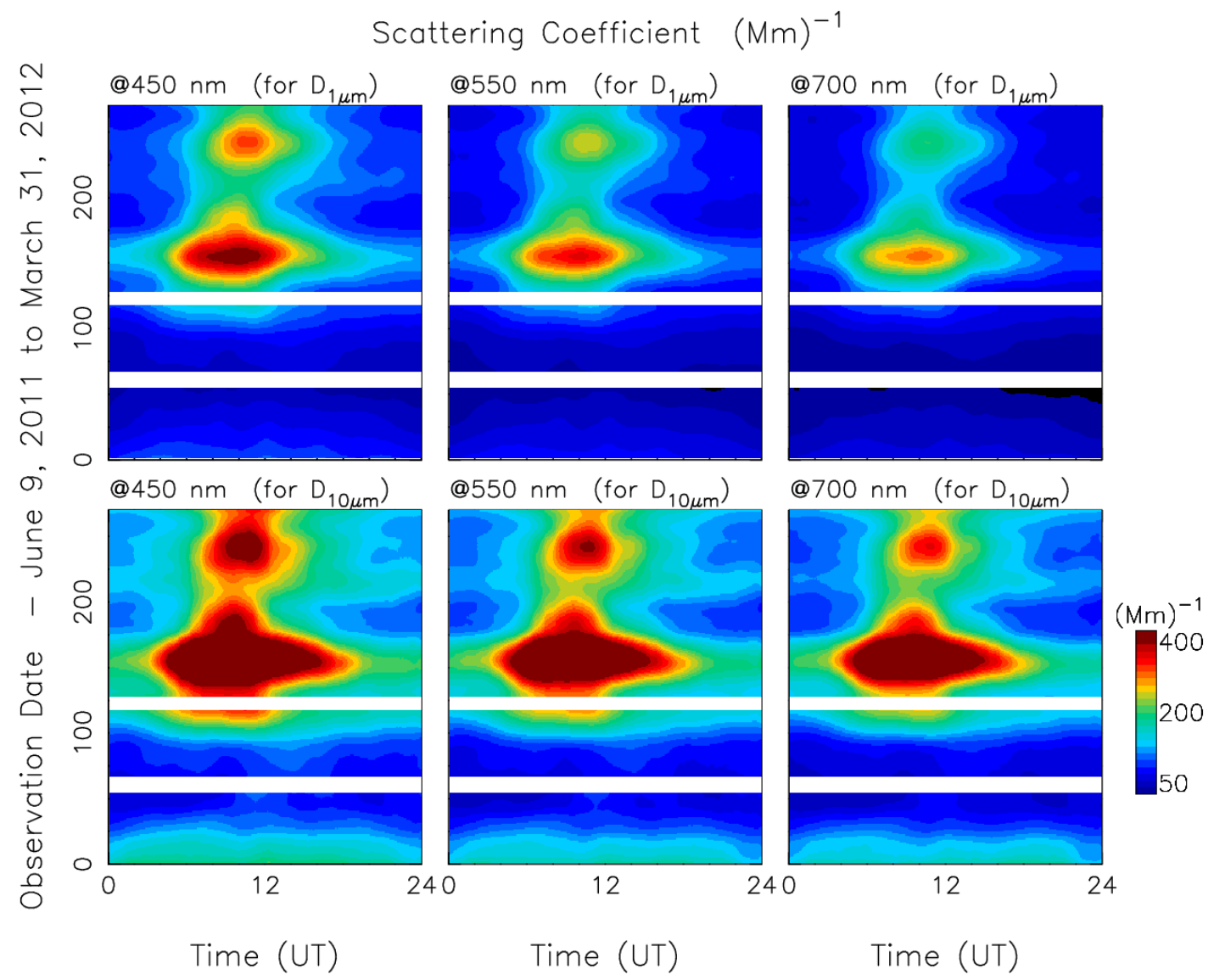

Supplementary Figure S2 - Temporal and spectral variation of aerosol scattering between June 9, 262011 to March 31, 20112.

27

28 
34 Note $\mathbf{C}$

35 The surface wind measurements from GVAX indicate that the wind direction in Nainital was commonly

36 from the northwest and southeast.

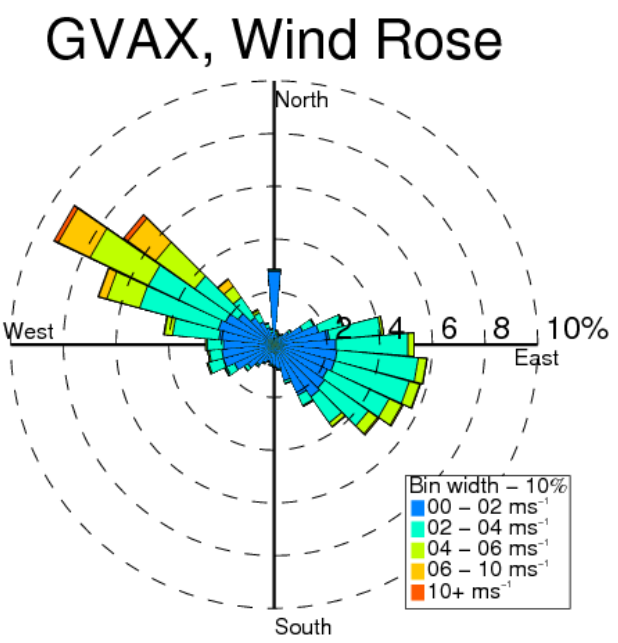

37

38 Supplementary Figure S3: Surface wind measurements from GVAX.

39

40

41 